\title{
Task-oriented treadmill exercise training in chronic hemiparetic stroke
}

\author{
Frederick M. Ivey, PhD; ${ }^{1-2}$ Charlene E. Hafer-Macko, MD; ${ }^{1,3}$ Richard F. Macko, MD ${ }^{1,3 *}$ \\ ${ }^{1}$ Geriatric Research, Education, and Clinical Center, Department of Veterans Affairs (VA) Maryland Health Care Sys- \\ tem, Baltimore VA Medical Center, Baltimore, MD; Departments of ${ }^{2}$ Medicine and ${ }^{3}$ Neurology, University of Mary- \\ land School of Medicine, Baltimore, $M D$
}

\begin{abstract}
Patients with stroke have elevated hemiparetic gait costs secondary to low activity levels and are often severely deconditioned. Decrements in peak aerobic capacity affect functional ability and cardiovascular-metabolic health and may be partially mediated by molecular changes in hemiparetic skeletal muscle. Conventional rehabilitation is time delimited in the subacute stroke phase and does not provide adequate aerobic intensity to reverse the profound detriments to fitness and function that result from stroke. Hence, we have studied progressive full body weight-support treadmill (TM) training as an adjunct therapy in the chronic stroke phase. Task-oriented TM training has produced measurable changes in fitness, function, and indices of cardiovascular-metabolic health after stroke, but the precise mechanisms for these changes remain under investigation. Further, the optimal dose of this therapy has yet to be identified for individuals with stroke and may vary as a function of deficit severity and outcome goals. This article summarizes the functional and metabolic decline caused by inactivity after stroke and provides current evidence that supports the use of TM training during the chronic stroke phase, with protocols and inclusion/exclusion criteria described. Our research findings are discussed in relation to associated research.
\end{abstract}

Key words: aerobic activity, ambulatory function, cardiovascular disease risk, exercise training, hemiplegia, metabolic health, physical deconditioning, rehabilitation, stroke, treadmill.

\section{PROBLEM OF POSTSTROKE DECONDITIONING}

Stroke is a leading cause of disability [1-4], with residual neurological deficits that persistently impair function and lead to profound physical deconditioning [5-6]. By limiting mobility and increasing fall risk, the hemiparetic gait that accompanies chronic stroke promotes a sedentary lifestyle, which leads to disability through deconditioning and "learned non-use" [7-8]. Peak cardiovascular fitness levels following hemiparetic stroke are roughly half those of age-matched sedentary individuals [5,9-10]. Further, the energy requirements of hemiparetic gait are elevated by 55 to 100 percent compared with age-matched control subjects [11-12]. This detrimental combination of poor peak exercise capacity and elevated energy demands for hemiparetic gait is termed diminished physiological fitness reserve [13]. The cardiovascular deconditioning coupled with the secondary body composition abnormalities that follow stroke

\footnotetext{
Abbreviations: ACSM = American College of Sports Medicine, $\mathrm{ADL}=$ activities of daily living, $\mathrm{BMI}=$ body mass index, $\mathrm{CVD}=$ cardiovascular disease, $\mathrm{ECG}=$ electrocardiogram, $\mathrm{HR}=$ heart rate, HRR $=$ HR reserve, IGT = impaired glucose tolerance, $\mathrm{MHC}=$ myosin heavy chain, $\mathrm{T} 2 \mathrm{DM}=$ type 2 diabetes mellitus, TM $=$ treadmill, TNF- $\alpha=$ tumor necrosis factor $-\alpha$, WIQ = Walking Impairment Questionnaire, VA = Department of Veterans Affairs, $\mathrm{VO}_{2}=$ peak oxygen consumption.

* Address all correspondence to Richard F. Macko, MD; VA Maryland Health Care System, Baltimore VA Medical Center, Geriatrics Service/GRECC (BT/GR/18), 10 North Greene St, Baltimore, MD 21201; 410-605-7000, ext 7063; fax: 410-605-7913. Email: rmacko@grecc.umaryland.edu

DOI: 10.1682/JRRD.2007.02.0035
} 
have implications for both function and cardiovascularmetabolic health.

The functional consequences of sedentary living after stroke are partially accounted for by detrimental effects on peak aerobic capacity. Peak oxygen consumption $\left(\mathrm{VO}_{2}\right)$ values in patients with stroke are below the level required for many basic activities of daily living (ADL) $[10,14]$. While fitness levels for age-matched nondisabled individuals far exceed the approximate range required for $\mathrm{ADL}, \mathrm{VO}_{2}$ levels for most patients with stroke fall in the middle of this zone [10] (Figure 1). Thus, many individuals with stroke must work to exhaustion or physiologically cross the anaerobic threshold to achieve basic ADL. These decreased fitness levels make certain activities either impossible or metabolically unsustainable for any extended period of time. Clearly, individuals with stroke can become functionally compromised based on decrements in aerobic capacity.

Reduced physical activity levels after stroke may also contribute to poor cardiovascular-metabolic health and an increased risk for recurrent cerebrovascular events [15]. Physical fitness and cardiovascular health are integrally related, with epidemiological studies indicating physical inactivity is associated with increased risk for incident stroke [16]. Moreover, cardiovascular deconditioning is strongly associated with insulin resistance and the metabolic syndrome, which is an independent predictor for increased risk of stroke, with higher population-

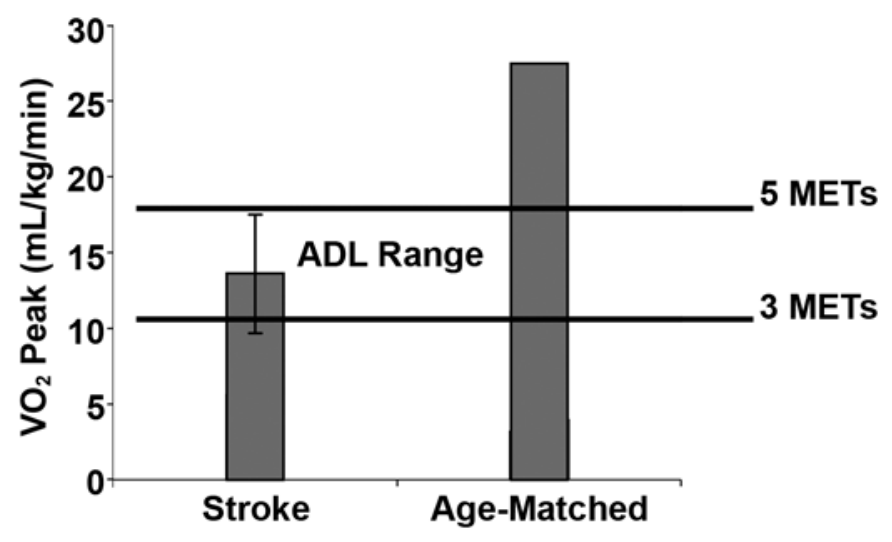

Figure 1.

Peak aerobic fitness levels in patients with chronic stroke relative to energy requirements for activities of daily living (ADL) $(N=131)$. MET = metabolic equivalent. Source: Reprinted with permission from Ivey FM, Macko RF, Ryan AS, Hafer-Macko CE. Cardiovascular health and fitness after stroke. Top Stroke Rehabil. 2005;12(1):1-16. [15735997] attributable risk than type 2 diabetes mellitus (T2DM) [17]. We and others report that insulin resistance is highly prevalent after stroke [18] and that the combined prevalence of impaired glucose tolerance (IGT) and T2DM may exceed 80 percent in individuals with chronic stroke [19]. Since IGT and T2DM prospectively predict two- and threefold increased risk for recurrent cerebrovascular events, respectively [20], this finding may constitute an important modifiable risk factor in secondary stroke prevention.

Physical inactivity can cause deconditioning across the phases of stroke recovery. Cardiac monitoring during conventional physical therapy reveals that low aerobic intensity is reached for $<3$ minutes in a typical physical therapy session [21]. Further, usual care for outpatient physical therapy, while quite variable in its application, was recently found to consist of only $9 \pm 5$ (mean \pm standard deviation) visits that end 30 to 180 days poststroke [22]. Hence, conventional subacute stroke rehabilitation likely does not provide adequate exercise to reverse profound deconditioning [16]. Following completion of subacute stroke rehabilitation, patients with stroke had extremely low activity levels that further contribute to deconditioning and poor cardiovascular health as measured by microprocessor-linked step activity monitoring [23-24]. We report that community-dwelling individuals with chronic stroke take a mean of only 1,400 steps/day, with only 83 steps/day at a higher walking intensity ( $>30$ steps/min). These extremely sedentary ambulatory activity levels are significantly associated with the poor fitness levels found in this population, a finding that argues for interventions that address the sedentary lifestyle so common among individuals with stroke. Evidence suggests that nearly half of patients with stroke decline in mobility function within a year and that these declines are linked to reduced exposure to physical therapy care [25-26]. Hence, continued worsening of aerobic capacity and metabolic health during the poststroke recovery period are well-documented and responsible for the comorbid cardiovascular conditions that represent the leading cause of death in this population [27-29]. Exercise interventions that go beyond the subacute stroke recovery period are needed for subjects with chronic stroke and hemiparesis to realize their potential for long-term functional motor recovery and cardiovascular health. 


\section{TISSUE-LEVEL ABNORMALITIES AFTER STROKE}

Numerous body composition and hemiparetic muscle tissue abnormalities in chronic stroke contribute to poor cardiovascular health and insulin resistance. These tissuelevel changes may be primary targets for exercise intervention strategies. Following stroke, gross hemiparetic skeletal muscular atrophy and increased intramuscular area fat are present [30]. These changes are clinically relevant given the data that confirm a strong relationship between thigh muscle mass and peak aerobic capacity after stroke [6]. In addition, elevated intramuscular fat is associated with insulin resistance and its complications [30]. Cellular changes in tissues of the paretic side may also negatively influence fitness, function, and cardiovascular disease (CVD) risk. Specifically, a deficit severity-dependent shift toward a fast-twitch muscle molecular phenotype in the paretic leg results in a more fatigable muscle fiber type that is more insulin resistant, which may contribute to the high incidence of IGT in this population [31-33]. Furthermore, nearly threefold elevated levels of tumor necrosis factor- $\alpha$ (TNF- $\alpha$ ) messenger RNA are reported in hemiparetic quadriceps muscle from patients with stroke compared with those from nonparetic legs and nonstroke control subjects [34]. Elevated TNF- $\alpha$ levels in skeletal muscle tissue are strongly linked to muscular wasting and insulin resistance in T2DM and advancing age and may contribute to the structural and metabolic abnormalities in hemiparetic skeletal muscle after stroke [35-38]. Since exercise training has been shown to reduce skeletal muscle TNF- $\alpha$ expression, which improves muscle strength and metabolic function in selected nonstroke populations [36], modification of inflammatory pathways through exercise therapy warrants consideration in the high CVD risk stroke population.

\section{TASK-ORIENTED TRAINING: COMBINING LOCOMOTOR LEARNING WITH AEROBIC EXERCISE}

Treadmill (TM) training is a task-oriented exercise model that assumes multiple physiological systems are integral to improving mobility recovery and optimizing cardiovascular health after stroke. The multiple systems approach accounts for potential effects on central nervous system motor control, cardiovascular fitness, muscle tissue characteristics, and whole-body metabolic health. Hence, full body weight-support TM training is designed to provide a task-repetitive locomotor training stimulus according to a progressive aerobic exercise formula.

The TM training model leverages three physiological principles: (1) improved reflexive gait patterning attributed to altered afferent proprioceptive input, (2) augmented locomotor entrainment with task-repetition that animal and human studies show is crucial for motor learning [39-40], and (3) progression of metabolic demands of the training stimulus by increasing velocity, grade, training session duration, and total program length. The latter principle of progression raises fundamental questions regarding which exercise formulas can optimally improve functional and metabolic health outcomes. As a starting point, we developed a conservative, low-intensity, progressive aerobic exercise program based on cardiac rehabilitation that is adjusted to baseline cardiopulmonary tolerance and gait deficit severity for patients with stroke [41-45]. The following sections provide an overview of our exercise protocols and safety data that have been used in randomized controlled studies on improving fitness and ambulatory function in older individuals with chronic hemiparetic gait following stroke.

\section{TREADMILL TESTING AND TRAINING PROTOCOLS}

Unique safety and feasibility issues must be considered when designing TM exercise protocols for individuals with stroke. The high incidence of medical and cardiovascular comorbid conditions warrants full preexercise evaluations complete with medical history, physical and cardiovascular examinations, and a review of basic blood test results to confirm eligibility for this type of therapy. Our clinical research experience with subjects with chronic stroke shows that approximately 70 percent have significant active medical issues that require contact with a physician for intervention before initiation of exercise training [41]. Most common are findings of previously undiagnosed T2DM, dyslipidemia, and coronary artery disease [41]. Proper medical screening must serve as a foundation for safety oversight related to exercise training.

Medical exclusions for exercise after stroke are consistent with American College of Sports Medicine (ACSM) criteria for high CVD risk subjects who participate in aerobic exercise [46]. In brief, our research exclusion 
criteria include symptomatic heart failure, unstable angina, peripheral arterial occlusive disease, aphasia (operationally defined as incapacity to follow two-point commands), dementia, untreated major depression, and other medical conditions that preclude participation in aerobic exercise, as previously reported [41]. These criteria are prospectively supported by our safety data tracking across $>10,000 \mathrm{TM}$ aerobic training sessions and $>400$ peak exercise tests in patients with hemiparetic stroke that reveal no study-related serious adverse events. However, these data do not represent the full range of patients who are eligible for exercise training and are inadequate for defining all potential medical contraindications unique to stroke. We consider hemodynamically significant carotid stenosis and recent stroke or transient ischemic attack ( $<4$ weeks) as contraindications to peak exercise testing. Strenuous physical exertion with exercise stress testing can produce arrhythmias and lower blood pressure in some individuals with cardiac disease. These cardiac events could trigger stroke in individuals with hemodynamic arterial stenosis or extend brain infarction in early poststroke when cerebral autoregulation is impaired and perfusion is more passively dependent on collateral circulation. Additional contraindications to regular TM training might include lower-limb joint arthritis and spastic deformity, depending on severity. Generally, orthopedic impediments should be reviewed on a case by case basis by a credentialed clinician for optimal adherence to safety principles. More data are needed to produce broader evidence-based safety recommendations for exercise testing and training in the stroke population.

After medical clearance, participants undergo a customized TM exercise stress test. This test is preceded by a 30-foot timed floor walk, which serves as a functional screen for ability to undertake the TM test and provides an estimate of TM walking velocity. Training is then individualized according to baseline gait function and fitness level and is progressed using conventional aerobic exercise formulas common to cardiac rehabilitation [41]. An overview of the protocols related to the use of TM exercise as a rehabilitation therapy is shown in Table $\mathbf{1 .}$

Most patients with hemiparetic stroke have poor selfefficacy for exercise and do not have prior experience with TM training, which necessitates a careful acclimatization to this new task. This acclimatization is accomplished with the $0^{\circ}$ incline TM tolerance test, which provides initial assessment of gait stability and gradual acclimatization to the task and identifies the target walk- ing velocity for subsequent peak effort exercise testing. A gait support belt is used as a safety measure. Since biomechanics of TM exercise differ from overground walking, most individuals experience a readily visible acclimatization period over about 3 to 7 minutes that is recognized by improved gait symmetry as the TM velocity is gradually increased according to tolerance [41].

After a 15-minute seated rest, individuals perform a constant velocity, peak effort, graded TM exercise test to volitional fatigue to assess the cardiopulmonary response to strenuous physical exertion. Participants are assured TM speed will be held constant at their individualized comfortable walking pace and inclines will be increased as tolerated. During this initial exercise test, open circuit spirometry is not used so that communication and patient comfort are optimized. Continuous electrocardiogram (ECG) and vital signs monitoring are used during this initial exercise stress test, consistent with ACSM safety criteria for high CVD risk populations.

Test termination criteria include a patient's request to stop at volitional fatigue, observed gait instability, or other stop criterion according to guidelines of the ACSM. Our initial TM stress testing cohort revealed previously undiagnosed asymptotic myocardial ischemia in 29 percent of stroke patients, which is consistent with other reports [45] and highlights the importance of careful cardiac screening in this high CVD risk population. Patients eligible for exercise training included those who could successfully complete 3 consecutive minutes of TM walking at $\geq 0.13 \mathrm{~m} / \mathrm{s}(\geq 0.3 \mathrm{mph})$ and $0^{\circ}$ incline without significant signs of myocardial ischemia or other contraindications to participation in regular aerobic exercise training. This minimal entry criterion ensures that the participants have adequate neuromotor capacity to participate in aerobic training [41].

\section{EXERCISE PRESCRIPTION AND TRAINING PROGRESSION}

Our training target in chronic stroke patients consists of three 40 to 45 minute sessions a week of TM walking at 60 to 70 percent of heart rate (HR) reserve (HRR), where target HR is determined according to the Karvonen formula

$$
\text { Target } \mathrm{HR}=\left[\left(\mathrm{HR}_{\text {peak }}-\mathrm{HR}_{\text {rest }}\right) \times \text { desired \% }\right]+\mathrm{HR}_{\text {rest }} \text {. }
$$


Table 1.

Six components of treadmill (TM) exercise program for individuals with gait impairment after stroke.

\begin{tabular}{lc}
\hline \multicolumn{1}{c}{ Test } & Purpose \\
\hline $\begin{array}{l}\text { Medical Examination \& Blood Tests } \\
\text { Timed 30-foot Floor Walk }\end{array}$ & $\begin{array}{l}\text { Medical eligibility \& risk factor optimization. } \\
\text { Establish functional eligibility for exercise test, estimate walking velocity } \\
\text { for TM, \& measure gait velocity as treatment outcome measure. } \\
\text { Zero-Incline TM Tolerance Test }\end{array}$ \\
$\begin{array}{ll}\text { Screening TM Exercise Stress Test } & \text { Identify cardiopulmonary response to strenuous exertion \& VO } \\
& \text { measured as outcome variable on separate day. }\end{array}$ \\
$\begin{array}{ll}\text { Initiate TM Aerobic Training } & \text { Formula of Karvonen used to define training parameters. } \\
\text { Repeat Exercise Test at 3 Months } & \text { Redefine optimal heart rate training parameters. }\end{array}$ \\
$\begin{array}{l}{ }^{*} \text { Open circuit spirometry for measuring peak oxygen consumption }\left(\mathrm{VO}_{2}\right) \text { is not used during screening exercise stress tests to maximize comfort and ensure proper } \\
\text { acclimatization during initial TM exposure. }\end{array}$ \\
\hline \hline
\end{tabular}

Training is initiated conservatively at 40 percent of HRR for durations of 10 to 15 minutes and advanced to the target range as tolerated. However, in patients on beta-blocker medications, the HR response to exercise is artificially reduced and a modified progression strategy is mandated for these individuals. Discontinuous training epochs of 3 to 5 minutes of TM walking with similar duration interval rests are preferred in highly deconditioned or more severely disabled patients who are incapable of continuous training. Total training duration is then advanced toward the target as tolerated. Handrail support is used, and a 5-minute TM warm-up and cool-down period at approximately 30 percent of HRR are phased into each workout as participants develop the necessary endurance for longer bouts of training. HR is monitored continuously by two-lead ECG (Polar Electro, Woodbury, New York), and blood pressure recordings are taken before, at the midpoint, and at the conclusion of each exercise session to ensure safety and document the intensity of the training session.

Progression of training workload is determined biweekly by monitoring each patient's gait, HR response, and self-reported fatigue level at the end of a training session. If no gait instability is observed, training speed is increased by $0.1 \mathrm{mph}$ increments until target training intensity is reached. Increase in TM grade (1\% increments) is used secondarily to achieve target aerobic intensity for those individuals who do not tolerate further TM velocity progression. Training duration is typically advanced approximately 5 minutes every 2 weeks, as tolerated, for a total of 45 minutes of training by the third month of training. For those subjects completing intermittent bouts of exercise, only duration is altered and subjects progress to one continuous bout of 15 minutes.
Using this protocol, we have 88 percent compliance for three time a week exercise attendance with no adverse events, somatic complaints, or overuse syndromes compared with matched control subjects who perform supervised stretching exercises [42]. Training duration can be expected to increase by 240 percent and training velocity by 35 percent across 6 months [42]. However, these limited data do not fully define stroke patients' ability to progress in training capacity nor do they define the training parameters needed to optimize functional and cardiovascular health gains. In our experience, individuals with chronic hemiparesis demonstrate substantial heterogeneity in their ability to progress with training; some individuals experience much greater gains. While this heterogeneity may be due in part to motivational-behavioral factors, the implications are that elements of training progression could be better cultivated. Further studies are underway to determine the precise exercise prescription and progression formulas that optimize gains in function and cardiovascular-metabolic health.

\section{PHYSIOLOGICAL EFFECTS OF TREADMILL TRAINING AFTER STROKE}

\section{Effects of Treadmill Training on Fitness and Econ- omy of Gait}

Results show that the time profile of cardiovascular fitness gains with regular TM exercise training are progressive and nearly equal across the initial 3 months and months 3 to 6 poststroke (Figure 2) [42]. No evidence of a plateau exists, which suggests that training even beyond 6 months may produce further benefits in peak fitness levels. Findings in this randomized study show that TM training improves fitness long after conventional rehabilitation care has ended and that the duration of exercise therapy to optimize these outcomes is at least 6 months 


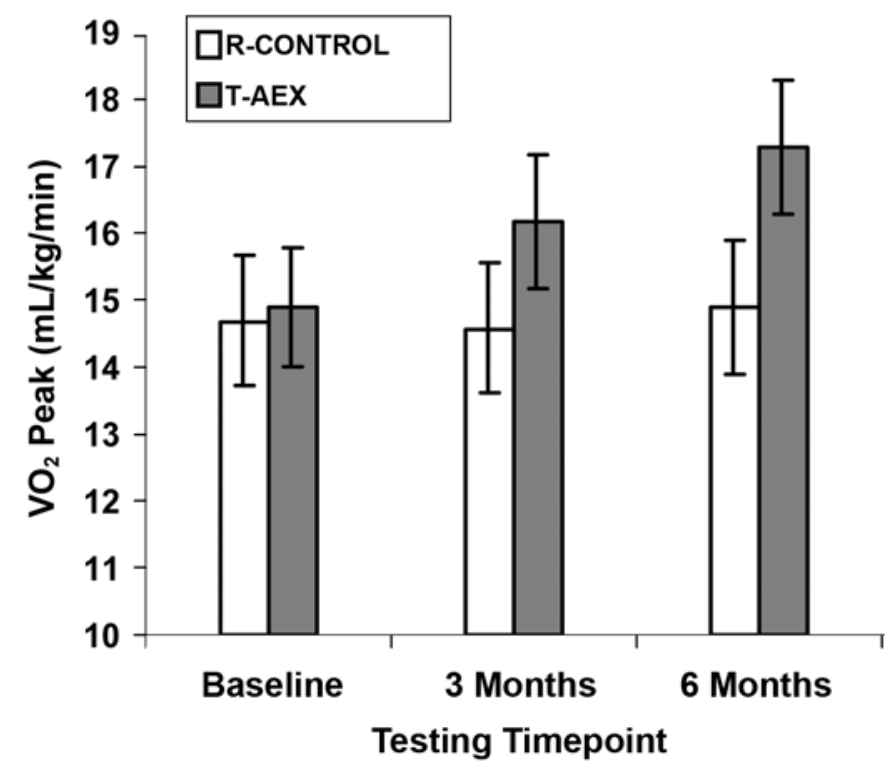

Figure 2.

Effects of 6-month treadmill exercise intervention on peak oxygen consumption $\left(\mathrm{VO}_{2}\right)$ after stroke. $\mathrm{R}-\mathrm{CONTROL}=$ control group, $\mathrm{T}-\mathrm{AEX}=$ treadmill aerobic exercise group. Source: Reprinted with permission from Macko RF, Ivey FM, Forrester LW, Hanley D, Sorkin JD, Katzel LI, Silver KH, Goldberg AP. Treadmill exercise rehabilitation improves ambulatory function and cardiovascular fitness in patients with chronic stroke: A randomized, controlled trial. Stroke. 2005;36(10):2206-11. [PMID: 16151035]

[42]. This result supports the rationale for long-term exercise after stroke, which is consistent with public health recommendations for sustained regular exercise to improve fitness and cardiovascular health for all Americans.

TM training improves physiological fitness reserve in chronic stroke patients by increasing $\mathrm{VO}_{2}$ while lowering the energy cost of hemiparetic gait [45]. These improvements may enhance functional mobility in chronic stroke by increasing peak ambulatory workload capacity and enabling basic mobility ADL to be performed at a lower percentage of peak exercise capacity [43].

\section{Treadmill Training and Ambulatory Function After Stroke}

Randomized study results also show that TM aerobic exercise therapy improves measured long-distance ambulatory capacity after stroke to a greater extent than an intervention that combines elements of conventional therapy [42]. TM aerobic exercise increased 6-minute walk distance by 30 percent, with most of the improvement occurring by 3 months (Figure 3). Although short-

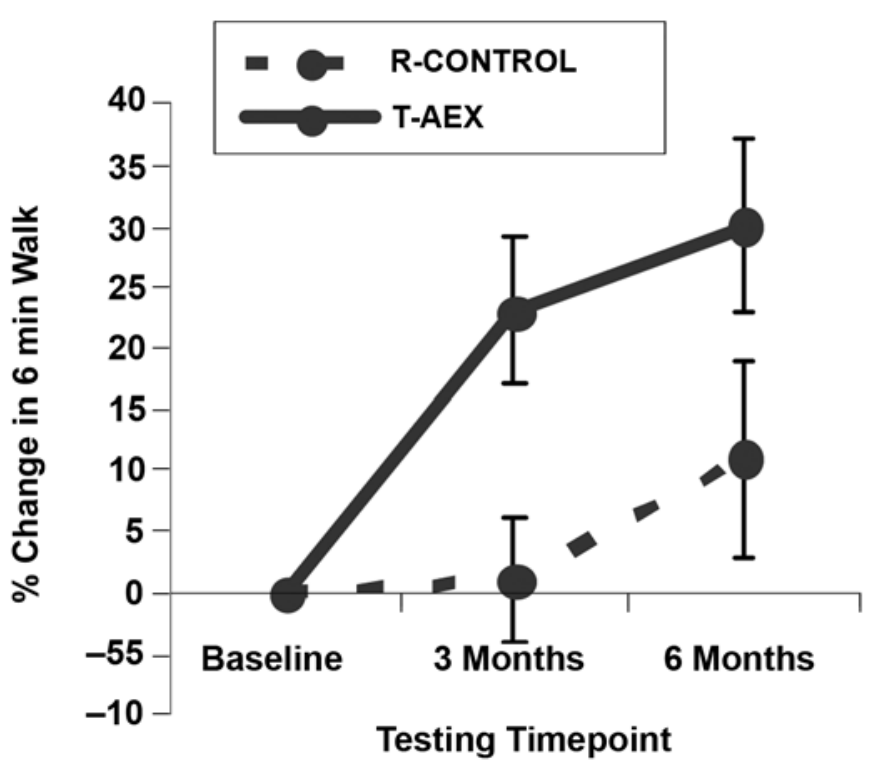

Figure 3.

Effects of 6-month treadmill exercise intervention on 6-minute walk distance after stroke. R-CONTROL = control group, T-AEX = treadmill aerobic exercise group. Source: Reprinted with permission from Macko RF, Ivey FM, Forrester LW, Hanley D, Sorkin JD, Katzel LI, Silver KH, Goldberg AP. Treadmill exercise rehabilitation improves ambulatory function and cardiovascular fitness in patients with chronic stroke: A randomized, controlled trial. Stroke. 2005; 36(10): 2206-11. [PMID: 16151035]

distance ambulatory 30-foot timed walks were improved with TM training, no significant differences were noted compared with control subjects [42].

\section{Self-Reported Functional Mobility (Walking Impairment Questionnaire) After Treadmill Training}

The Walking Impairment Questionnaire (WIQ) assesses the effects of exercise on self-reported walking distance, speed, and stair climbing. Progressive TM aerobic exercise improves WIQ distance scores (45 \pm 7 to $70 \pm$ 7 , mean \pm standard error) compared with control subjects (50 \pm 7 to $56 \pm 8)(p<0.05$, between groups) [42]. These findings suggest that training regimen significantly affects community-based activity levels and preserves fitness, function, and metabolic health after stroke.

\section{Predictors of Response to Treadmill Training}

No clinical or demographic factors correlated with the absence of TM aerobic exercise treatment response in any of the measured outcomes. Regression analyses showed no link between adaptations in $\mathrm{VO}_{2}$ or 6-minute 
walk performance and age at entry, latency since stroke, initial $\mathrm{VO}_{2}$, or gait deficit severity. However, degree of progression in selected TM training parameters over 6 months did relate to the nature of the exercise-mediated adaptations. Specifically, change in training session duration did relate to improvements in 6-minute walk distances $(r=0.41, p<0.05)$ but not $\mathrm{VO}_{2}(r=0.19, p=$ 0.34). Conversely, increases in TM training velocity over 6 months significantly correlated with increases in $\mathrm{VO}_{2}$ $(r=0.43, p<0.05)$ but not change in 6 -minute walk distances $(r=0.17, p=0.46)$.

\section{Leg Strength and Spasticity}

The effects of TM exercise on muscle strength and spastic reflexes have been assessed after stroke [47]. Fourteen subjects age $66 \pm 3$ years with residual gait deviations because of chronic stroke ( $>6$ months) underwent repeated measures of reflexive and volitional (concentric and eccentric) torque on the hamstring musculature bilaterally with the use of isokinetic dynamometry. Torque output was measured at four angular velocities (30,60, 90, and $120 \%$ s). After 3 months of low-intensity aerobic exercise three times a week, significant main effects were noted for concentric torque production. Torque/time production in the concentric mode also improved significantly in the paretic $(50 \%, p<0.01)$ and nonparetic hamstrings (31\%, $p<0.01)$. Eccentric torque/time production increased by 21 percent $(p<$ $0.01)$ and 22 percent $(p<0.01)$ in the paretic and nonparetic hamstrings, respectively. Passive (reflexive) torque/time generation in the paretic hamstrings decreased by 11 percent $(p<0.03)$. Reflexive torque/time was unchanged in the nonparetic hamstrings $(p=0.45)$. These findings provide evidence that progressive TM aerobic exercise training improves volitional torque and torque/time generation and reduces reflexive torque/time production in the hemiparetic limb [47].

\section{Overground Walking Changes After Treadmill Training}

The purpose of Patterson et al.'s study was to investigate how TM exercise changes spatial and temporal gait parameters and how these changes relate to changes in overground walking function [48]. In that study, significant increases in 30-foot walk times and 6-minute walk distances were accompanied by increased walking velocity (22\%), stride length (13\%), and cadence (7\%). The investigators concluded that TM aerobic exercise improves gait velocity secondary to increased stride length and, to a lesser extent, cadence. Further, this increase in gait performance capacity was carried over into multiple ambulatory conditions including short- and long-distance walking and walking with and without a usual prescribed assistive device.

\section{Effects of Treadmill Training on Markers of Cardiovascular-Metabolic Risk and Body Composition After Stroke}

Exercise training has been shown to improve a number of cardiovascular and metabolic risk factors in nonstroke populations [49], including hypertension [50], hyperlipidemia [51], obesity [52], insulin resistance [49], and inflammation [53]. However, few studies have specifically assessed the effects of exercise training on markers of CVD risk in the stroke population [16]. Rimmer et al. reported that exercise training improved dyslipidemia and measures of regional adiposity in morbidly obese individuals with stroke (mean body mass index [BMI] >35) [54]. Additionally, Fletcher et al. reported that a home exercise training program improved left ventricular ejection fraction and lipid profiles in chronically disabled individuals, the majority of whom were individuals with stroke [55]. Although insulin resistance and IGT are prospectively linked to stroke risk, no prior studies have looked at these parameters across a training intervention in stroke. Our preliminary data show that 6 months of mild-moderate TM training lowers fasting hyperinsulinemia by 24 percent in individuals with chronic stroke. This result is clinically relevant given the epidemiological data that show a strong prospective link between hyperinsulinemia and cardiovascular morbidity and mortality. Interestingly, the body composition findings in the same group of volunteers with stroke showed no change in percent body fat, fat-free mass, and total body weight across the intervention period (Table 2).

Unlike Rimmer et al.'s study, our study population had a more normal BMI $(<30)$, which demonstrates that cardiovascular-metabolic adaptations with exercise after stroke are possible without concomitant changes in body composition. This finding highlights the possibility that exercise-induced changes in whole-body metabolism could be mediated by cellular and molecular adaptations in skeletal muscle. For example, preliminary data from our laboratory show that TM training may cause a shift back toward a more normal myosin heavy chain (MHC) isoform distribution in the paretic leg of patients with 
JRRD, Volume 45, Number 2, 2008

Table 2.

Body composition change for treadmill intervention vs stretching protocol intervention (mean \pm standard error).

\begin{tabular}{lcccccc}
\hline \multirow{2}{*}{ Variable } & \multicolumn{2}{c}{ Treadmill $(\boldsymbol{n}=\mathbf{2 6})$} & & \multicolumn{2}{c}{ Control $(\boldsymbol{n}=\mathbf{2 0})$} & \multicolumn{1}{c}{$\boldsymbol{p}$-Value $($ group $\times$} \\
\cline { 2 - 3 } & Baseline & $\mathbf{6 ~ M o n t h s}$ & & Baseline & 6 Months & 0.44 \\
Bime interaction)
\end{tabular}

stroke (Figure 4). This reduction in the fast-twitch muscle fiber type could improve both insulin sensitivity and function according to previous findings.

In addition, other relevant molecular mechanisms may exist that are related to improvements in metabolism and function after stroke. Specifically, we have begun to investigate the effect of TM exercise on markers of inflammation in stroke skeletal muscle, having already identified unusually high levels of these markers in the paretic leg at baseline.

\section{SUMMARY AND FUTURE RESEARCH}

The high prevalence of extreme sedentary living after stroke is a massive public health problem that causes debilitating levels of deconditioning as well as cardiovascular morbidity and mortality. Conventional rehabilitation is time delimited within the subacute stroke phase and does not provide adequate aerobic intensity to reverse the profound detriments to fitness and function. However, Eich et al. showed that TM training can be combined with more conventional therapies during early stroke recovery phases for optimal improvements in walking capacity [56]. Further, our randomized studies of task-oriented aerobic training in chronic stroke ( $>6$ months) show improvements in peak aerobic capacity, economy of gait, long-distance ambulatory capacity, self-reported physical activity, muscle strength, spasticity, and gait dynamics. Preliminary data show the first evidence that exercise may also favorably alter indices of insulin sensitivity after stroke in the absence of any changes to body composition. In a small number of patients with stroke, we report that TM exercise training may restore the slowtwitch MHC muscle molecular phenotype, which could partially account for improvements in insulin sensitivity and function. However, the extent to which exercise training can reverse the structural and metabolic abnormalities in hemiparetic muscle is unknown and requires further investigation.

Although TM exercise studies show progressive gains in fitness and ambulatory function over 6 months of training, the optimal dose of this therapy has yet to be identified for patients with stroke and may vary as a function of deficit severity as well as other factors. Specifically, consideration must be made in terms of intensity and duration of the TM training stimulus that may affect outcomes in the realms of function and metabolism. Followup studies are currently underway that build upon the work of Pohl et al. [57] and others [58-59] by randomizing (a)

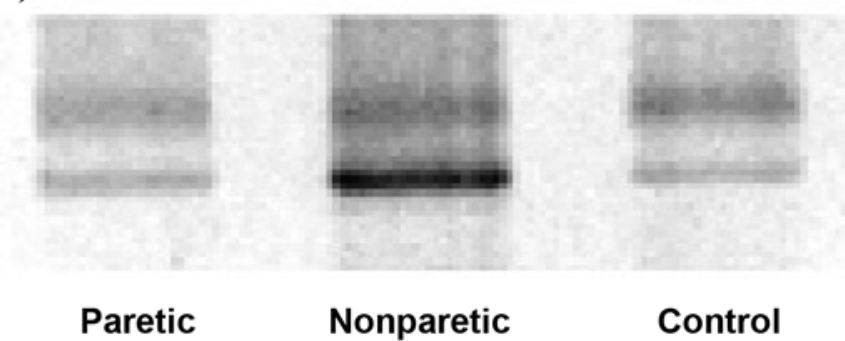

(b)

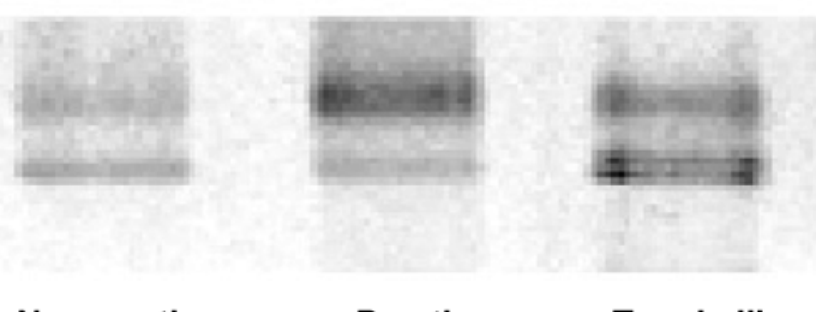

$\begin{array}{lll}\text { Nonparetic } & \text { Paretic } & \text { Treadmill }\end{array}$

Figure 4.

Silver-stained gel electrophoresis of shift toward more normal myosin heavy chain isoform distribution after treadmill training in individuals with chronic stroke between (a) control and (b) treadmill training participants. 
patients with stroke to high- and low-speed TM training groups. Our intent is to test the effect of differing training strategies on a variety of functional and metabolic outcomes. Our preliminary data suggest that higher exercise intensity training, advanced according to both TM speed and grade, is crucial for improving cardiovascular fitness, while greater dose in the form of task repetition over a longer training session predicts gains in ambulatory function. Future research efforts will need to observe the effects of precise manipulation of training parameters in individuals with stroke of varying disability profiles to determine the ideal training regimens. The training protocols may necessarily vary according to differing outcome goals in the categories of function, fitness, and cardiovascular-metabolic health.

\section{ACKNOWLEDGMENTS}

This material was based on work supported by the Department of Veterans Affairs (VA), Rehabilitation Research and Development, Exercise and Robotics Center of Excellence (Dr. Macko); the Baltimore VA Medical Center, Geriatric Research, Education, and Clinical Center; the VA Stroke Research Enhancement Award Program (Dr. Macko); the National Institutes of Health (grant NIH-NIA K01-AG019242 to Dr. Ivey); and the Claude D. Pepper Older Americans Independence Center (grant P60AG12583).

The authors have declared that no competing interests exist.

\section{REFERENCES}

1. Gresham GE, Phillips TF, Wolf PA, McNamara PM, Kannel WB, Dawber TR. Epidemiologic profile of long-term stroke disability: The Framingham study. Arch Phys Med Rehabil. 1979;60(11):487-91. [PMID: 508073$]$

2. Sacco RL, Wolf PA, Kannel WB, McNamara PM. Survival and recurrence following stroke. The Framingham study. Stroke. 1982;13(3):290-95. [PMID: 7080120]

3. American Heart Association. Heart and stroke facts. Dallas (TX): American Heart Association; 1993.

4. Post-Stroke Rehabilitation Guideline Panel. Post-stroke rehabilitation: Clinical practice guideline No. 16. Rockville (MD): U.S. Department of Health and Human Services, Public Health Service, Agency for Health Care Policy and Research (AHCPR); 1995. AHCPR publication 95-0662.
5. Potempa K, Lopez M, Braun LT, Szidon JP, Fogg L, Tincknell T. Physiological outcomes of aerobic exercise training in hemiparetic stroke patients. Stroke. 1995; 26(1):101-5. [PMID: 7839377]

6. Ryan AS, Dobrovolny L, Silver KH, Smith GV, Macko RF. Cardiovascular fitness after stroke: Role of muscle mass and gait deficit severity. J Stroke Cerebrovasc Disord. 2000; 9:1-8.

7. Taub E. Somatosensory deafferentation research with monkeys: Implications for rehabilitation medicine. In: Ince LP, editor. Behavioral psychology in rehabilitation medicine: Clinical applications. Baltimore (MD): Williams \& Wilkins; 1980. p. 371-401.

8. Taub E, Miller NE, Novack TA, Cook EW 3rd, Fleming WC, Nepomuceno CS, Connell JS, Crago JE. Technique to improve chronic motor deficit after stroke. Arch Phys Med Rehabil. 1993;74(4):347-54. [PMID: 8466415]

9. Chu KS, Eng JJ, Dawson AS, Harris JE, Ozkaplan A, Gylfadóttir S. Water-based exercise for cardiovascular fitness in people with chronic stroke: A randomized controlled trial. Arch Phys Med Rehabil. 2004;85(6):870-74.

[PMID: 15179638]

10. Ivey FM, Macko RF, Ryan AS, Hafer-Macko CE. Cardiovascular health and fitness after stroke. Top Stroke Rehabil. 2005;12(1):1-16. [PMID: 15735997]

11. Corcoran PJ, Jebsen RH, Brengelmann GL, Simons BC. Effects of plastic and metal leg braces on speed and energy cost of hemiparetic ambulation. Arch Phys Med Rehabil. 1970;51(2):69-77. [PMID: 5437126$]$

12. Gersten JW, Orr W. External work of walking in hemiparetic patients. Scand J Rehabil Med. 1971;3(1):85-88. [PMID: 5156160$]$

13. McArdle WD, Katch FI, Katch VL. Exercise physiology: Energy, nutrition, and human performance. 4th ed. Baltimore (MD): Williams \& Wilkins; 1996.

14. Ivey FM, Hafer-Macko CE, Macko RF. Exercise rehabilitation after stroke. NeuroRx. 2006;3(4):439-50.

[PMID: 17012057]

15. Sacco RL, Gan R, Boden-Albala B, Lin IF, Kargman DE, Hauser WA, Shea S, Paik MC. Leisure-time physical activity and ischemic stroke risk: The Northern Manhattan Stroke Study. Stroke. 1998;29(2):380-87. [PMID: 9472878$]$

16. Gordon NF, Gulanick M, Costa F, Fletcher G, Franklin BA, Roth EJ, Shephard T; American Heart Association Council on Clinical Cardiology, Subcommittee on Exercise, Cardiac Rehabilitation, and Prevention; the Council on Cardiovascular Nursing; the Council on Nutrition, Physical Activity, and Metabolism; and the Stroke Council. Physical activity and exercise recommendations for stroke survivors: An American Heart Association scientific statement from the Council on Clinical Cardiology, Subcommittee on Exercise, Cardiac Rehabilitation, and Prevention; the Council on Cardiovascular 
Nursing; the Council on Nutrition, Physical Activity, and Metabolism; and the Stroke Council. Circulation. 2004; 109(16):2031-41. [PMID: 15117863]

17. Najarian RM, Sullivan LM, Kannel WB, Wilson PW, D’Agostino RB, Wolf PA. Metabolic syndrome compared with type 2 diabetes mellitus as a risk factor for stroke: The Framingham Offspring Study. Arch Intern Med. 2006; 166(1):106-11. [PMID: 16401818]

18. Kernan WN, Inzucchi SE, Viscoli CM, Brass LM, Bravata DM, Shulman GI, McVeety JC, Horwitz RI. Impaired insulin sensitivity among nondiabetic patients with a recent TIA or ischemic stroke. Neurology. 2003;60(9):1447-51. [PMID: 12743229]

19. Ivey FM, Ryan AS, Hafer-Macko CE, Garrity BM, Sorkin JD, Goldberg AP, Macko RF. High prevalence of abnormal glucose metabolism and poor sensitivity of fasting plasma glucose in the chronic phase of stroke. Cerebrovasc Dis. 2006;22(5-6):368-71. [PMID: 16888377]

20. Vermeer SE, Sandee W, Algra A, Koudstaal PJ, Kappelle LJ, Dippel DW; Dutch TIA Trial Study Group. Impaired glucose tolerance increases stroke risk in nondiabetic patients with transient ischemic attack or minor ischemic stroke. Stroke. 2006;37(6):1413-17. [PMID: 16627787]

21. MacKay-Lyons MJ, Makrides L. Cardiovascular stress during a contemporary stroke rehabilitation program: Is the intensity adequate to induce a training effect? Arch Phys Med Rehabil. 2002;83(10):1378-83. [PMID: 12370872]

22. Duncan P, Studenski S, Richards L, Gollub S, Lai SM, Reker D, Perera S, Yates J, Koch V, Rigler S, Johnson D. Randomized clinical trial of therapeutic exercise in subacute stroke. Stroke. 2003;34(9):2173-80. [PMID: 12920254]

23. Michael KM, Allen JK, Macko RF. Reduced ambulatory activity after stroke: The role of balance, gait, and cardiovascular fitness. Arch Phys Med Rehabil. 2005;86(8): 1552-56. [PMID: 16084807]

24. Shaughnessy M, Michael KM, Sorkin JD, Macko RF. Steps after stroke: Capturing ambulatory recovery. 2005;36(6): 1305-7. [PMID: 15879321]

25. Jørgensen HS, Nakayama H, Raaschou HO, Vive-Larsen J, Støier M, Olsen TS. Outcome and time course of recovery in stroke. Part II: Time course of recovery. The Copenhagen Stroke Study. Arch Phys Med Rehabil. 1995;76(5): 406-12. [PMID: 7741609]

26. Jørgensen HS, Nakayama H, Raaschou HO, Olsen TS. Recovery of walking function in stroke patients: The Copenhagen Stroke Study. Arch Phys Med Rehabil. 1995; 76(1):27-32. [PMID: 7811170]

27. Roth EJ. Heart disease in patients with stroke: Incidence, impact, and implications for rehabilitation. Part 1: Classification and prevalence. Arch Phys Med Rehabil. 1993;74(7): 752-60. [PMID: 8328899]
28. Roth EJ. Heart disease in patients with stroke. Part II: Impact and implications for rehabilitation. Arch Phys Med Rehabil. 1994;75(1):94-101. [PMID: 8291971]

29. Wade DT, Skilbeck CE, Wood VA, Langton Hewer R. Long-term survival after stroke. Age Ageing. 1984;13(2): 76-82. [PMID: 6731168]

30. Ryan AS, Dobrovolny CL, Smith GV, Silver KH, Macko RF. Hemiparetic muscle atrophy and increased intramuscular fat in stroke patients. Arch Phys Med Rehabil. 2002;83(12):1703-7. [PMID: 12474173]

31. De Deyne PG, Hafer-Macko CE, Ivey FM, Ryan AS, Macko RF. Muscle molecular phenotype after stroke is associated with gait speed. Muscle Nerve. 2004;30(2):209-15. [PMID: 15266637]

32. Frontera WR, Grimby L, Larsson L. Firing rate of the lower motoneuron and contractile properties of its muscle fibers after upper motoneuron lesion in man. Muscle Nerve. 1997;20(8):938-47. [PMID: 9236783]

33. Jakobsson F, Edström L, Grimby L, Thornell LE. Disuse of anterior tibial muscle during locomotion and increased proportion of type II fibres in hemiplegia. J Neurol Sci. 1991;105(1):49-56. [PMID: 1795169]

34. Hafer-Macko CE, Yu S, Ryan AS, Ivey FM, Macko RF. Elevated tumor necrosis factor-alpha in skeletal muscle after stroke. Stroke. 2005;36(9):2021-23. [PMID: 16109906]

35. De Alvaro C, Teruel T, Hernandez R, Lorenzo M. Tumor necrosis factor alpha produces insulin resistance in skeletal muscle by activation of inhibitor kappaB kinase in a p38 MAPK-dependent manner. J Biol Chem. 2004;279(17): 17070-78. [PMID: 14764603]

36. Greiwe J, Cheng B, Rubin DC, Yarasheski KE, Semenkovich CF. Resistance exercise decreases skeletal muscle tumor necrosis factor alpha in frail elderly humans. FASEB J. 2001;15(2):475-82. [PMID: 11156963]

37. Hunter RB, Stevenson E, Koncarevic A, Mitchell-Felton $\mathrm{H}$, Essig DA, Kandarian SC. Activation of an alternative NF-kappaB pathway in skeletal muscle during disuse atrophy. FASEB J. 2002;16(6):529-38. [PMID: 11919155]

38. Saghizadeh M, Ong JM, Garvey WT, Henry RR, Kern PA. The expression of TNF alpha by human muscle. Relationship to insulin resistance. J Clin Invest. 1996;97(4):1111-16. [PMID: 8613535]

39. Classen J, Knorr U, Werhahn KJ, Schlaug G, Kunesch E, Cohen LG, Seitz RJ, Benecke R. Multimodal output mapping of human central motor representation on different spatial scales. J Physiol. 1998;512(Pt 1):163-79. [PMID: 9729626]

40. Nudo RJ, Milliken GW, Jenkins WM, Merzenich MM. Use-dependent alterations of movement representations in primary motor cortex of adult squirrel monkeys. J Neurosci. 1996;16(2):785-807. [PMID: 8551360] 
41. Macko RF, Ivey FM, Forrester LW. Task-oriented aerobic exercise in chronic hemiparetic stroke: Training protocols and treatment effects. Top Stroke Rehabil. 2005;12(1):45-57. [PMID: 15736000$]$

42. Macko RF, Ivey FM, Forrester LW, Hanley D, Sorkin JD, Katzel LI, Silver KH, Goldberg AP. Treadmill exercise rehabilitation improves ambulatory function and cardiovascular fitness in patients with chronic stroke: A randomized, controlled trial. Stroke. 2005;36(10):2206-11. [PMID: 16151035]

43. Macko RF, DeSouza CA, Tretter LD, Silver KH, Smith GV, Anderson PA, Tomoyasu N, Gorman P, Dengel DR. Treadmill aerobic exercise training reduces the energy expenditure and cardiovascular demands of hemiparetic gait in chronic stroke patients. A preliminary report. Stroke. 1997;28(2):326-30. [PMID: 9040684]

44. Macko RF, Katzel LI, Yataco A, Tretter LD, DeSouza CA, Dengel DR, Smith GV, Silver KH. Low-velocity graded treadmill stress testing in hemiparetic stroke patients. Stroke. 1997;28(5):988-92. [PMID: 9158639]

45. Macko RF, Smith GV, Dobrovolny CL, Sorkin JD, Goldberg AP, Silver KH. Treadmill training improves fitness reserve in chronic stroke patients. Arch Phys Med Rehabil. 2001;82(7):879-84. [PMID: 11441372]

46. Whaley MH, Brubaker PH, Otto RM, Armstrong LE, for the American College of Sports Medicine (ACSM). ACSM's guidelines for exercise testing and prescription. 7th ed. Baltimore (MD): Lippincott, Williams \& Wilkins; 2006.

47. Smith GV, Silver KH, Goldberg AP, Macko RF. “Taskoriented” exercise improves hamstring strength and spastic reflexes in chronic stroke patients. Stroke. 1999;30(10): 2112-18. [PMID: 10512915]

48. Patterson SL, Rodgers MM, Macko RF, Forrester LW. Effect of treadmill exercise training on spatial and temporal gait parameters in subjects with chronic stroke: A preliminary report. J Rehabil Res Dev. 2008;45(2):221-28.

49. Villareal DT, Miller BV 3rd, Banks M, Fontana L, Sinacore DR, Klein S. Effect of lifestyle intervention on metabolic coronary heart disease risk factors in obese older adults. Am J Clin Nutr. 2006;84(6):1317-23. [PMID: 17158411]

50. Pescatello LS, Franklin BA, Fagard R, Farquhar WB, Kelley GA, Ray CA; American College of Sports Medicine. American College of Sports Medicine position stand. Exercise and hypertension. Med Sci Sports Exerc. 2004; 36(3):533-53. [PMID: 15076798]
51. Stone NJ, Bilek S, Rosenbaum S. Recent National Cholesterol Education Program Adult Treatment Panel III update: Adjustments and options. Am J Cardiol. 2005;96(4A): 53E-59E. [PMID: 16098845]

52. Wannamethee SG, Shaper AG, Whincup PH. Modifiable lifestyle factors and the metabolic syndrome in older men: Effects of lifestyle changes. J Am Geriatr Soc. 2006;54(12): 1909-14. [PMID: 17198498$]$

53. Dekker MJ, Lee S, Hudson R, Kilpatrick K, Graham TE, Ross R, Robinson LE. An exercise intervention without weight loss decreases circulating interleukin-6 in lean and obese men with and without type 2 diabetes mellitus. Metabolism. 2007;56(3):332-38. [PMID: 17292721]

54. Rimmer JH, Riley B, Creviston T, Nicola T. Exercise training in a predominantly African-American group of stroke survivors. Med Sci Sports Exerc. 2000;32(12):1990-96. [PMID: 11128841]

55. Fletcher GF, Blair SN, Blumenthal J, Caspersen C, Chaitman B, Epstein S, Falls H, Froelicher ES, Froelicher VF, Pina IL. Statement on exercise. Benefits and recommendations for physical activity programs for all Americans. A statement for health professionals by the Committee on Exercise and Cardiac Rehabilitation of the Council on Clinical Cardiology, American Heart Association. Circulation. 1992;86(1):340-44. [PMID: 1617788]

56. Eich HJ, Mach H, Werner C, Hesse S. Aerobic treadmill plus Bobath walking training improves walking in subacute stroke: A randomized controlled trial. Clin Rehabil. 2004; 18(6):640-51. [PMID: 15473116$]$

57. Pohl M, Mehrholz J, Ritschel C, Ruckriem S. Speeddependent treadmill training in ambulatory hemiparetic stroke patients: A randomized controlled trial. Stroke. 2002; 33(2):553-58. [PMID: 11823669]

58. Kwakkel G, Wagenaar RC, Twisk JW, Lankhorst GJ, Koetsier JC. Intensity of leg and arm training after primary middle-cerebral-artery stroke: A randomised trial. Lancet. 1999;354(9174):191-96. [PMID: 10421300]

59. Sullivan KJ, Knowlton BJ, Dobkin BH. Step training with body weight support: Effect of treadmill speed and practice paradigms on poststroke locomotor recovery. Arch Phys Med Rehabil. 2002;83(5):683-91. [PMID: 11994808]

Submitted for publication February 15, 2007. Accepted in revised form June 28, 2007. 